\title{
(HMGovernment
}

\section{CONSULTATION ON MODERN WORKPLACES}

iii) Working time regulations 


\title{
5. Working Time Regulations
}

\author{
This chapter sets out proposals on changes to the UK's Working Time \\ Regulations. These concern the interaction of annual leave with sick, \\ maternity, adoption, parental, and paternity leave. Changes are necessary \\ to ensure that UK legislation is consistent with the Working Time Directive, \\ as interpreted in a number of judgments of the Court of Justice of the \\ European Union (CJEU).
}

\section{The current system}

1. The UK's Working Time Regulations (WTR) ${ }^{1}$ give effect to the European Working Time Directive (WTD), ${ }^{2}$ and aim to ensure workers' health and safety by giving adequate rest and annual leave periods, and setting limits on hours worked. The Directive created the right for EU workers to a minimum of four weeks' annual leave each year (set out in Regulation 13 of the WTR). In 2009, Regulation 13A of the WTR extended the entitlement by 1.6 weeks to 5.6 weeks (although it cannot exceed 28 days). This consultation seeks views on the proposals to alter UK law in light of recent judgments by the Court of Justice of the European Union (CJEU; previously the European Court of Justice (ECJ)).

\section{Statutory annual leave entitlement in the UK}

Under the WTR workers are statutorily entitled to a total of 5.6 weeks' annual leave (limited to 28 days). Rights to further leave may arise from employment contracts. The rights conferred include:

- Regulation 13 leave (4 weeks), which gives effect to the Working Time Directive requirement.

- Regulation 13A leave (an additional 1.6 weeks), which is purely a matter of domestic law and represents the number of bank holidays in a year, but need not be used for them.

- Regulation 14, which gives workers an entitlement to payment in lieu of the untaken statutory entitlement for that leave year upon termination of employment.

2. It is important to emphasise that our proposals in this area are not directly related to the possibility of negotiations on a further revision of the WTD itself, on which the European Commission has begun consultations with the EU social partners. These discussions remain

\footnotetext{
${ }^{1}$ http://webarchive.nationalarchives.gov.uk/+/berr.gov.uk/whatwedo/employment/employmentlegislation/working-time-regs/index.html

${ }^{2}$ Directive 2003/88/EC.
} 
at a very early stage, but should they develop further, the Government's key policy aims in any negotiations will be to maintain the individual opt-out from the 48-hour maximum working week, and to increase flexibility by finding a solution to the current problems caused by separate CJEU judgments on on-call time and compensatory rest. We will also continue to monitor and, where appropriate, take into account any further CJEU judgments or changes in EU policy in this area.

\section{The case for change}

3. There have been a number of judgments in the CJEU relating to the interaction of the annual leave entitlement with other types of leave. Stringer ${ }^{3}$ and Pereda ${ }^{4}$ concern the interaction of sickness absence and annual leave; Gomez ${ }^{5}$ covered maternity leave; and Land Tirol $^{6}$ parental leave. The principles established in respect of sickness and the annual leave entitlement under the Working Time Directive were:

i. Workers continue to accrue annual leave entitlement during sickness absence (Stringer);

ii. Workers can choose to take annual leave at the same time as being absent due to sickness (Stringer);

iii. Workers whose employment terminates in a year during which they have been away from work due to sickness are entitled to the same termination payment for untaken annual leave as any other worker (Stringer);

iv. Workers who fall sick during scheduled annual leave can reschedule the annual leave within the same leave year (Pereda); and

v. Workers who were unable to take annual leave due to sickness absence and who have not had the opportunity to take it again within the same leave year must be able to carry it forward into the next leave year (Pereda).

4. The Gomez and Land Tirol judgments mean that a worker cannot lose his right to annual leave because of maternity and parental leave.

5. Although the WTR are consistent with the first four points above, they currently prohibit the carry over of the Regulation 13 entitlement into another leave year. The Regulation 13A

\footnotetext{
${ }^{3}$ Stringer and Others v Her Majesty's Revenue and Customs, CJEU case C-520/06, joined with Schultz-Hoff v Deutsche Rentenversicherung Bund, C-350/06.

${ }^{4}$ Pereda v Madrid Movilidad SA, ECJ case C-277/08.

${ }^{5}$ Merino Gomez v Continental Industrias del Caucho SA, CJEU case C-342/01.

${ }^{6}$ Zentralbetriebsrat der Landeskrankenhauser Tirols v Land Tirol, CJEU case C-486/08.
} 
entitlement can only be carried forward into the next leave year where this is provided for in a relevant agreement. ${ }^{7}$

6. Member States are obliged to implement European Directives as interpreted by the CJEU. Where domestic law is incompatible with the meaning of a provision in light of a CJEU judgment, the UK is obliged to amend that law to achieve compatibility. In making amendments to address these judgments, however, the Government also intends to pursue three additional objectives:

- Limiting the application of Working Time Directive: in making changes to the WTR we propose to limit the impact on business of the CJEU rulings so that significant elements of the rulings on sick absence will be restricted to the EU leave entitlement and not the additional UK entitlement. We are also seeking views on making other changes to the WTR to introduce greater flexibility around the operation of statutory annual leave.

- Provide greater certainty: until the regulations are amended there will remain an element of uncertainty for businesses.

- Support family friendly policies: the proposed changes to the WTR will also support the other family-friendly proposals in this consultation, in particular by ensuring that parents taking family-related leave do not lose out on annual leave.

\section{Our proposals}

\section{Sickness absence}

\section{Carryover and rescheduling of annual leave}

7. We propose amending the WTR so that the current prohibition on carrying over leave will not apply in some circumstances. This deals with the key point of incompatibility between the Pereda judgment and the current WTR. Where a worker has been unable to take his annual leave due to sickness absence and it is not possible to schedule the leave in the current leave year, he will be able to carry over annual leave into the following leave year. Similarly, where a worker falls sick during scheduled annual leave he will be able to reschedule the annual leave at a later date, including carrying it over if it is not possible to reschedule in the current leave year.

8. However, we propose that the employer should nevertheless be able to insist that leave that is unused in such circumstances should be taken in the current leave year if there is still an opportunity to do so. Conversely, we also intend to allow employers to require leave that is untaken due to sickness to be carried forward to the following leave year if there are good business reasons for this. This is consistent with the observation in the Pereda judgment that overriding reasons relating to the interests of the employer's undertaking can be taken into account when scheduling leave.

\footnotetext{
${ }^{7}$ This is laid out in regulations $13(9)(a)$ and $13 A(7)$ respectively of the WTR.
} 
9. We are also interested in hearing views on any other areas where greater flexibility could be introduced regarding the scheduling of annual leave (see paragraphs 28 to 31).

\section{Example: situations in which leave could be carried over}

A worker plans to use a fortnight of his leave entitlement by taking a holiday towards the end of the leave year, but falls ill and is off work for the whole of the last two months of that year. In such circumstances, the employee would be able to carry the untaken fortnight's leave forward to the next leave year.

A worker in a retail business - where the leave year runs from January to December - is off sick for all of September, October and November, leaving the worker with a week of unused leave entitlement. On returning to work in December the employer is concerned at the prospect of the employee taking the outstanding week's leave during the company's busiest trading time, since little cover will be available. The employer therefore requires the remaining week's leave to be carried forward to the next leave year.

\section{Limitation on statutory leave that can be carried over}

10. We propose to allow employers to limit the entitlement to carry leave forward to the four week leave entitlement under Regulation 13 (the EU leave entitlement). Employers would not be obliged to allow carryover in respect of the additional entitlement under Regulation 13A. For example, if a worker had only taken three weeks and was prevented from taking the remaining 2.6 weeks by sickness, then the employer would only be obliged to allow carryover of one week.

11. We also propose that a worker's entitlement on termination of employment to a payment in lieu of untaken leave under Regulation 14 will include payment in respect of any untaken carried over leave (although allowing employers to limit the carryover to the four-week entitlement will reduce the potential costs).

\section{Example: payments on termination}

Due to sickness a worker carries over 10 days of annual leave into the following leave year. He then has his employment terminated half-way through the year.

The worker's employer has to pay him for any untaken leave entitlement that he is due upon termination. The employer therefore has to calculate how much of the current year's pro-rated leave entitlement is untaken and pay the the worker for this. The employer must also pay him for any of the 10 days carried over that have not yet been taken.

12. We also propose to limit the ability to reschedule annual leave within the leave year where a worker has been sick whilst on scheduled annual leave (i.e. principle (iv) in paragraph 3 above) to the four weeks Regulation 13 leave. Employers would not be obliged to allow rescheduling in respect of the additional entitlement under Regulation 13A.

13. For this to work, employers and workers will need to know the consequences of sickness absence coinciding with scheduled annual leave. Both parties will need to know if the worker, when he falls sick, is taking Regulation 13 leave (which would give rise to a right to reschedule/carry forward) or other leave (which would not give such rights). 
14. Which type of leave a worker is using at any particular time could be subject to a local agreement, be it a workplace or collective agreement or a contractual term. For example, a contract could provide that bank holidays will count as the Regulation 13A entitlement, with no right to reschedule if the worker falls ill on those days. The bank holiday would still count as paid annual leave. This may be helpful where the workplace shuts down for bank holidays or for some other period during the year, and it is particularly inconvenient to reschedule such leave.

15. In the absence of local agreements, we propose that the WTR should specify the order in which leave would be deemed to be taken. The most logical order would be that Regulation 13 leave is taken first during a leave year, followed by all other types of leave. This order could result in less leave being carried over as the four weeks leave would be taken first. It would not be possible to address the bank holiday issue through this default approach, as taking leave on bank holidays is not a statutory entitlement but a contractual one.

\section{Example: carry-over and rescheduling of leave}

A business only allows the rescheduling and carry-over of leave of the Regulation 13 entitlement, and allocates this to the first four weeks of leave taken by a worker.

A worker employed by this business, has already taken three weeks of leave in the current year and plans to take another break of 2.6 weeks (thus using up his full statutory leave entitlement). He then falls ill for the whole of this period of scheduled leave and takes the appropriate steps to notify his employer.

When he returns to work, the worker will now only be entitled to reschedule the first week of annual leave for which he was sick, losing the remaining 1.6 weeks of leave. If the timing of the illness is such that there is no opportunity for him to retake his leave before the end of the leave year, he could carry the week over into the following leave year.

16. It is important to stress that employers would still need to be aware of other contractual or statutory obligations such as the disability discrimination provisions of the Equality Act 2010. Where sickness absence may be attributable to disability, employers should consider whether limiting carryover or rescheduling of leave to the four-week entitlement would be consistent with their Equality Act obligations.

Consultation Questions

36. Do you agree with the proposal to allow employers to limit the carry over of leave in sickness cases to the four-week entitlement under Regulation 13? Please explain your response.

37. Do you agree with the proposal to allow employers to limit the right to reschedule leave in the event of sickness to the four-week entitlement under Regulation 13? Please explain your response.

38. Do you agree with the proposal that the Working Time Regulations be amended to specify the order in which leave is deemed to be taken, subject to contrary provision in a relevant agreement or contract? Please explain your response. 


\section{Accrual of annual leave during sickness absence}

17. The CJEU judgments make clear that statutory annual leave must continue to accrue during sickness absence. Although the WTR do not need to be amended on this point, we have considered whether also to limit accrual in such circumstances to Regulation 13 leave.

18. The arguments in favour of this are that it may in principle reduce costs for business, particularly where workers are on long periods of sickness absence. For example, if a worker was off sick for a full leave year and chose to take his annual leave simultaneously, the employer would only need to pay the worker's full wage for four weeks and not 5.6 weeks.

19. However, our view is that such an approach may provide more complications than solutions. If applied to all periods of sickness absence, including short isolated periods of sickness, it would appear unworkable. For instance, if a worker was sick for a month, week or day, an employer would have to calculate the appropriate proportion of Regulation 13A not accrued. Record-keeping arrangements would need to be changed to keep track of such calculations. Furthermore, as an employer will inevitably never know how much sickness absence a worker will have until the end of the leave year, it would be impossible to calculate before then precisely how much leave a worker was due. By this time, of course, the worker may have taken all of his leave.

20. In light of this we do not consider this a viable option. We consider that the fairly small savings would be more than offset by the additional complexities and the administrative costs.

\section{Consultation Question}

39. Do you agree that there is no merit in amending the Working Time Regulations to limit the accrual of annual leave during sickness absence to the four-week entitlement under Regulation 13? Please explain your response.

\section{Family leave}

21. As noted in paragraph 4, there have been CJEU rulings that have similar implications for carry-over when annual leave cannot be taken due to absence on maternity and parental leave. In the context of the Government's commitment to support family friendly policies, we propose to amend the WTR to allow carry-over of leave which is untaken due to absence on maternity, adoption, parental and paternity leave (including additional paternity leave). This would in due course also apply to the proposed new flexible parental leave rights. We do not think these measures will have a significant impact on employers or employees as in most cases there is sufficient notice to plan for these types of leave, reducing the need to carry over annual leave. We are not proposing to extend this to other types of leave beyond those listed above.

22. As with leave untaken due to sickness, we propose that employers would also be able to take into account business interests when rescheduling annual leave untaken due to familyrelated leave, giving them some scope to require leave to be carried over to the following leave year. 
23. We consider that this will provide a further incentive for parents to make use of their familyrelated leave rights. In particular, it may help to encourage fathers to make use of their entitlements and thus play a more active role in the bringing up of their children.

24. Unlike the proposals around sick leave, the Government does not propose in these circumstances to limit the carry-over provision to Regulation 13 leave, as to do so would appear inconsistent with the relevant CJEU judgments.

\section{Consultation Question}

40. Do you foresee any problems or difficulties with the approach proposed on the interaction of annual and family-related leave? Please explain your response.

\section{Notification requirements}

25. Subject to contrary provision in a relevant agreement, Regulation 15 of the WTR already sets out the notice period that a worker must give their employer for taking annual leave. This is generally twice the length of the intended leave period. An employer can specify periods when leave must or cannot be taken and can also cap the amount of leave taken at any one time. In light of these existing provisions we think that employers have sufficient scope to control and plan for their workers' annual leave even if this is rescheduled because of sickness absence. Our proposals will also mean that an employer can insist that leave which is untaken due to sickness absence must be taken in the current leave year, where possible, rather than being carried forward. There will also be the additional flexibility for the employer to defer leave until the following year when this can be justified in terms of business need.

26. As far as notification of sickness is concerned, workers will usually have to follow applicable sickness policies in order to count the leave as sickness absence and be able to reschedule untaken leave. These could include the process for workers to notify sickness, and any evidence required such as a fit note (formerly a sick note). Employers will need to ensure that their practices do not make it too difficult for workers to exercise their rights.

27. We are aware that businesses will have concerns around the abuse of these provisions. These abuses may arise where a worker on annual leave tries to claim falsely that he was sick so that he can take more annual leave at a later date. We believe this type of behaviour should be capable of being deterred in most cases by employers' notification procedures for sickness absence, either as they exist now or as they may be amended in light of these proposed changes. We would, however, be interested to hear proposals from employers concerned that this may not be the case.

\section{Consultation Questions}

41. Do you agree that existing statutory notification provisions will be sufficient to enable employers to manage issues arising from the proposed changes to the Working Time Regulations? If not, what additional statutory requirements might be helpful in relation to rescheduling or carrying over leave?

42. More generally, are there any additional issues that you would like to raise in relation to the proposed amendments around the interaction of annual leave with sick leave and family leave? 


\section{Further flexibility on annual leave}

28. The proposals on annual leave in this consultation document respond to CJEU judgments regarding workers' entitlement to paid annual leave in certain circumstances. Our proposals have been framed with careful consideration of the impact on both employers and employees, and we are in particular seeking to maintain useful flexibility for both sides. However, we would also like to take this opportunity to seek views on the possibility of making other changes to the WTR which would introduce greater flexibility around the operation of statutory annual leave.

29. The extent to which flexibility can be increased is of course restricted by the provisions of the WTD, as interpreted by the CJEU. We have identified two areas in which changes might be possible in the interests of increasing flexibility:

- We could consider allowing employers to 'buy out' the additional leave entitlement under Regulation 13A (i.e. the additional entitlement of up to 1.6 weeks of leave which goes beyond the four-week EU entitlement). The basis on which this could occur could be a matter for agreement between an employee and his employer, or for negotiation between an employer and employees' representatives. The WTR would need to be amended to make this possible as currently they expressly prohibit all buying-out of statutory leave. The principle could not, however, be extended to the four weeks' Regulation 13 entitlement, since allowing 'buying out' of this would be inconsistent with the provisions of the WTD.

- We could consider a provision to enable employers to require employees to carry over the additional leave entitlement under Regulation 13A (or part of it) in all cases of overriding business need. Under our other proposals in this consultation, employers would in any case be able to require leave to be carried over in the case of sickness (and employees would be allowed to carry it over in the case the family-friendly leave). But we could go further and allow this flexibility in all cases of overriding business need.

30. It is important to underline that the second possibility would require an employer to demonstrate that there was a genuinely overriding business need, so as to stop employees being deprived of annual leave within the leave year without real justification. Guidance would be provided on the question of what might or might not constitute circumstances meeting this test. It is also important to stress that the possibility of employers making changes to employees' entitlements following any amendment of the WTR may be constrained by contractual terms, which could not of course be altered without agreement.

31. This is preliminary thinking, and further analysis and an impact assessment would be necessary before taking these or any alternative or additional proposals forward. We would welcome views on these matters, together with any further proposals in this context that would be consistent with the legal constraints of the WTD. 


\section{Consultation Questions}

43. Would you support amendment of the Working Time Regulations to allow:

- 'buy out' by agreement of the additional 1.6 weeks leave entitlement under Regulation 13A; and

- employers to require the carry-over of the additional 1.6 weeks leave entitlement under Regulation 13A in cases of overriding business need?

44. Do you have any other proposals for ways in which the operation of the annual leave provisions could be made more flexible, consistent with the requirements of the Working Time Directive?

45. Do you have any comments on the analysis contained within the Impact Assessment? 


\section{(C) Crown copyright 2011}

You may re-use this information (not including logos) free of charge in any format or medium, under the terms of the Open Government Licence. To view this licence, visit www.nationalarchives.gov.uk/doc/open-government-licence/ or write to the Information Policy Team, The National Archives, Kew, London TW9 4DU, or e-mail: psi@nationalarchives.gsi.gov.uk.

This publication is also available on the BIS website at www.bis.gov.uk

If you require this publication in an alternative format, email enquiries@bis.gsi.gov.uk, or call 02072155000 .

\section{URN 11/699-1}

